\title{
WiFi Based Indoor Navigation System for Closed Buildings Using Smart Phones
}

\author{
Gayatri Hushe \\ Email: gayatrihushe@gmail.com \\ Rakesh Suryawanshi \\ Email: rakeshsuryawanshi@acpce.ac.in
}

Received: 01 April 2021; Accepted: 20 May 2021; Published: 08 June 2021

\begin{abstract}
The easy access and availability of wireless technologies and mobile computing and the internet have led to new opportunities in developing mobile applications whose purpose is to make people's life easier. Nowadays, a person can possess more than one mobile device intended for different usage such as communication, entertainment, office work. This GPS (Global Positioning System) is one of the equipment that helps to find the way to reach the destination from the source. The use of GPS as a tool to determine the location of course has a shortage when used indoors such as Shopping Malls, Hotels, College, etc. Our project is a small attempt towards an affordable and efficient indoor navigation system in which users need to turn on mobile Wi-Fi and scan the available Wi-Fi network and its strength. If the WiFi with maximum strength is found then application will show the current location then the user can select the destination from the available options. Due to this application will show the path to the user in form of text also the application can speak the path to the selected destination.
\end{abstract}

Index Terms: Indoor Navigation, Global Positioning System, Wi-Fi, Smart Phones

\section{Introduction}

People are increasingly relying upon their smartphones to solve some of their common daily problems. One such problem that smartphones have not yet solved is Indoor Navigation. At the time of writing, there is not a single low-cost scalable mobile phone solution available in the market that successfully navigated a user from one position to another position within the indoor.

Nowadays, with the rising a large number of buildings (eg. schools, shopping malls, airports, etc), have made it difficult for day-to-day visitors to remember the interior map of each of these places accurately. There may be an information helpdesk that could provide proper guidance to users, but some buildings may not have such a facility or the helpdesk is not close by and cannot be readily located in the building. Moreover, the visitor may further lose his/her direction inside the building, while trying to find the nearest helpdesk which itself is a time-consuming task. It is hence more convenient if the visitors could simply view the current location along with the interior map of the building on their mobile phone, wherever and whenever it is necessary for the user. To solve this problem, we are going to design a mobile application that will be able to estimate the position of a user within a building and guide the user to reach a particular destination by using WiFi technology.

\section{Literature Review}

There were some studies that were carried out on the topic related to our project. All the studies were having some major demerits making that project to give less fruitful results. Some of them are stated below.

A paper titled "The Active Badge Location System" was the earliest location system was the Active Badge developed by Olivetti Research Laboratory where the user was wearing a badge that emitted infrared signals. In this, The accuracy of the location depends on the number of receivers also it required line-of-sight between the receivers and the badge[1]. The second approach titled "Passive RFID-based Indoor Positioning System, An Algorithmic Approach". RFID has also demonstrated its capability in location-based systems. One famous location sensing system using RFID technology is known as mTag. The mTag architecture uses fixed RFID readers located within the environment and a passive RFID tag attached to a mobile phone or PDA. In this, the cost of deploying and implementing this kind of system can be very high. Also, there was one-way communication links and multipath effects[2]. 
The third approach titled "Here cast: an open infrastructure for location-based services using WiFi".Herecast is another system using the WLAN technology. It allows the WIFI- enabled client device to determine its location by listening to signals from known access points within the environment. The system creates a database where the MAC address of the access point is stored together with the symbolic name of the location. In the localization process, the position of the user is the one associated with the access point with the strongest signal strength. It allows the WIFIenabled client device to determine its location by listening to signals from known access points within the environment. In this, if an accesspoint is faulty or has been removed, the position of the user may be distorted[3].

The next approach titled "Place Lab: Device Positioning Using Radio Beacons in the Wild".The PlaceLab system is similar to Herecast in that it allows the client device to automatically obtain its location by listening to signals from the access point. PlaceLab stores the MAC address broadcast by each access point as well as its longitude and latitude in the client device. Therefore, for when the client device receives a signal from each of the access points, the location is calculated as the average of retrieved longitude and latitude. In this, for each location-aware application, you would haveto fetch a list of access points rather than one request for the whole system[4].

One more approach titled "QR code-based navigation system for closed building using smartphones". QR codes are used in this context to provide location information to the user optically. QR codes will be used all across the building to carry the information required for the navigation system. The mobile application will use the QR codes to provide indoor navigation for the user. In this, the main demerit is that there is no handling of floor layout[5].

\section{Objectives}

The objectives of the proposed system comprises of :

- High accuracy : The application should consistently guide users to their destinations for a particular distance.

- Low-cost : The application should not require any expensive infrastructural changes to obtain accurate positioningdata.

- Intuitive user interface (UI) : The application should have an easy-to-use UI that displays navigation hints correctly based on the user's current state.

- Robustness : The application should function normally even when some signals are not available while scanning.

\section{Proposed System}

In the Proposed System, a user makes use of his/her phone Wi-Fi to locate the current location. When the application starts the user needs to turn on the Wi-Fi. After that users need to scan for the available network on our premises. Then the user can find out the known Wi-Fi location from this application. This application shows the respective location map in the form of an image. If the application could not find the known Wi-Fi then this application shows the complete map of premises in the form of an image. If the user wants to go to a specific location then the user needs to select the destination location from the premises. After that this application will speak with the location path. Text-To-Speech is a method that converts speech from text.

Let's see some brief description of the proposed system :

\section{A. Overview}

In this indoor navigation system, the Android software platform and Android development kits are used. A smartphone application is developed in the Android platform for the collection of WiFi signal strengths and signal strength data are collected and imported into the respective collection objects which will be called by the main activity for the navigation. The smartphone user uses the Android application to receive the current position. The brief details on the platform, devel- opment kits and some assistant tools used in this project are described below.

1) Android Platform: Android is an open-source OS that is designed by Google primarily for touchscreen mobile devices such as smartphones and tablet computers. It provides various device drivers and management modules, class libraries, and frameworks such as lightweight database SQLite and Web kit browser. With the rapid increase of the Android smartphone market share, the Android OS has become a widely used OS in the smartphone industry.

2) Collection Framework $::$ The Collection is a framework in Java that provides an architecture to store and manipulate the group of objects. Java Collections has predefined methods for searching, sorting, insertion, manipulation, and deletion data. 
3) Package of Android :: Provides classes to manage WiFi functionality on the device. The WiFi APIs provide a means by which applications can communicate with the lower-level wireless stack that provides WiFi network access. Some other API features include the ability to scan, add, save, terminate and initiate WiFi connections. In this project, we have used API as follows :

- $\quad$ android.net.wifi.ScanResult : It is used to describe the information about a detected access point.

- android.net.wifi.WifiInfo : It is used to describe the state of any Wifi connection that is active or is in the process of being set up.

- android.net.wifi.WifiManager : It is used to provide the primary API for managing all aspects of WiFi connectivity.

4) Text to Speech Module : : It is used to synthesize speech from the text to create a sound. In this project, we have implemented TextToSpeech.OnInitListener for getting notified of the completion of the initialization. When we are done using the TextToSpeech instance, a shutdown() method is called to release the native resources used by the TextToSpeech engine.

\section{B. Architecture}

A Wi-Fi-based indoor positioning system is developed us- ing an Android smartphone to receive WiFi signal strength measurements. This system is easy to implement and low cost since only Access Points (AP) are required for hardware, in addition to the Android smartphone.

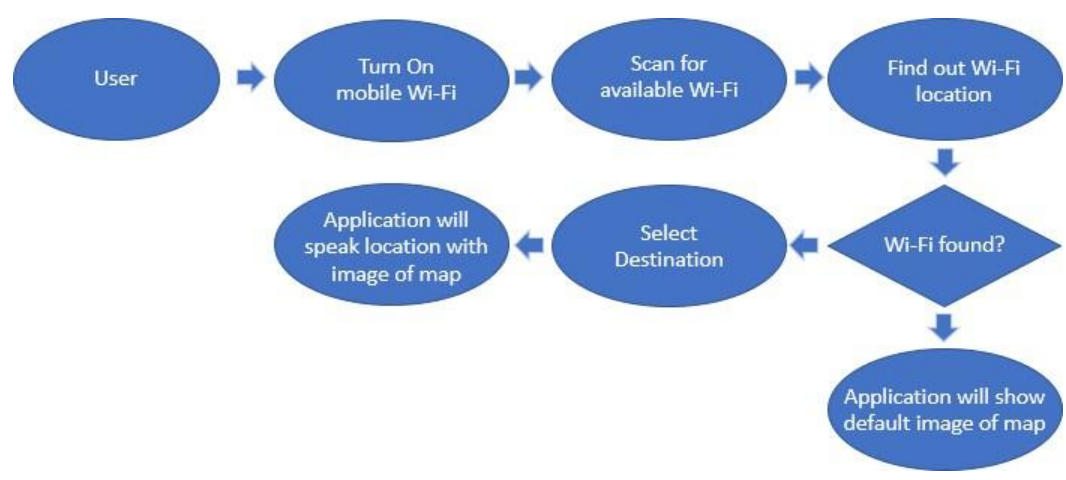

Fig.1. Architecture of Proposed Model

\section{Use Case Diagram}

The system will tend to only one type of interaction i.e user. The interaction of the user with the system is as per the following use case diagram :

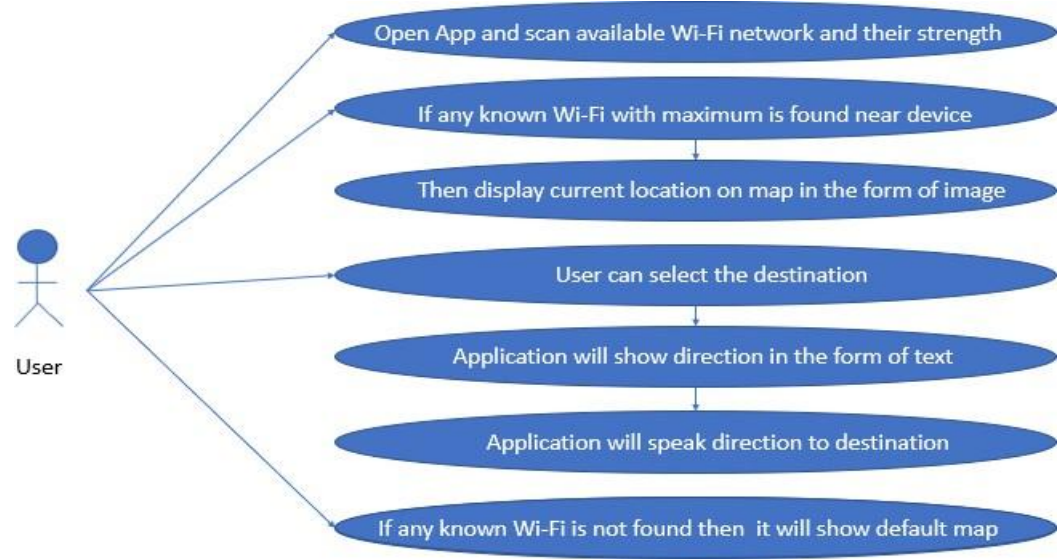

Fig. 2. Architecture of Proposed Model

D. Activity Diagram 
The activity diagram gives an overview of the Indoor Navigation System. The activity diagram contains two points: one is the initial point and the other is the endpoint. The activity diagram starts with an initial point which shows the flow of the application by the user. While the first step after the initial point performed is opening the app and scanning the available Wi-Fi Network and its Strength. If any known Wi-Fi Network with maximum strength is identified near the device then the application will display the map in the form of an image. After this, the user can select the destination. The application will show the direction in the form of text. Also, the application can speak directions. If the application could not identify any Wi-Fi Network then it will show the default map image.

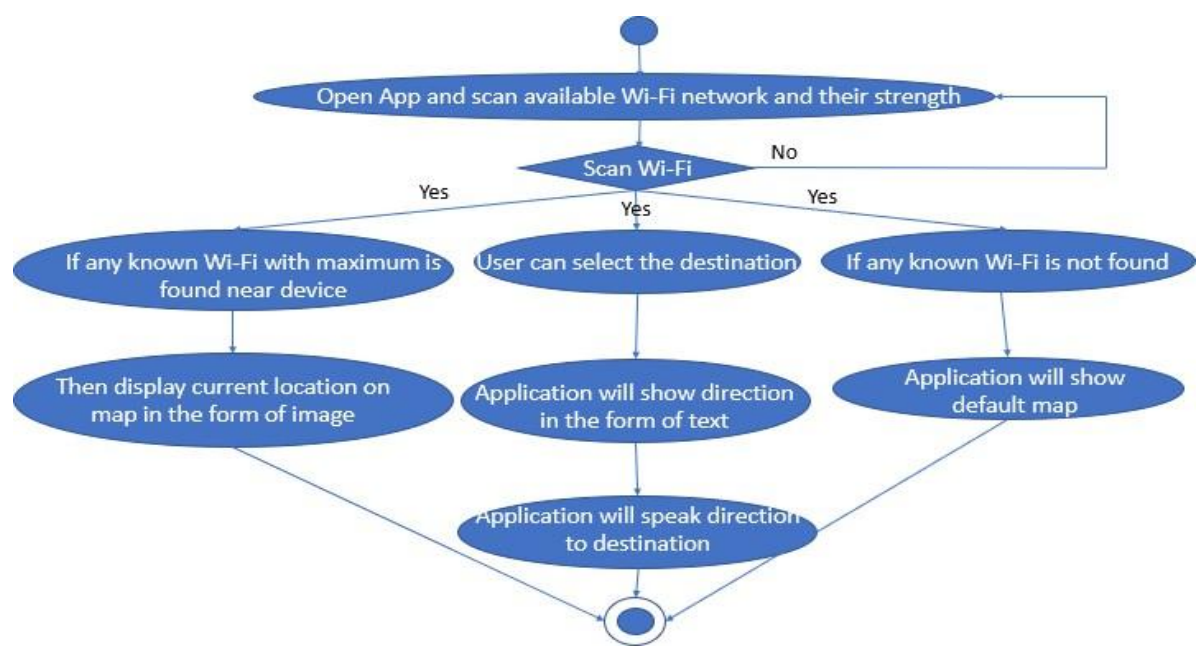

Fig. 3. Architecture of Proposed Model

\section{E. DFD Diagram}

Data Flow Diagram (DFD) provides a visual representation of the flow of information within a system. The data flow diagram shows four levels.

5) Level 0 DFD: In level 0, the user has to open the application and scan the available Wi-Fi Network and its strength.

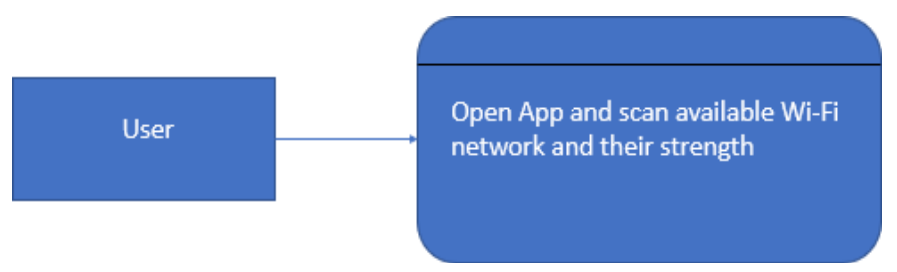

Fig. 4. DFD Level 0

6) Level 1 DFD: In level 1, if any known Wi-Fi Network with maximum strength is identified near the device then the application will display the map in the form of an image onthe device.

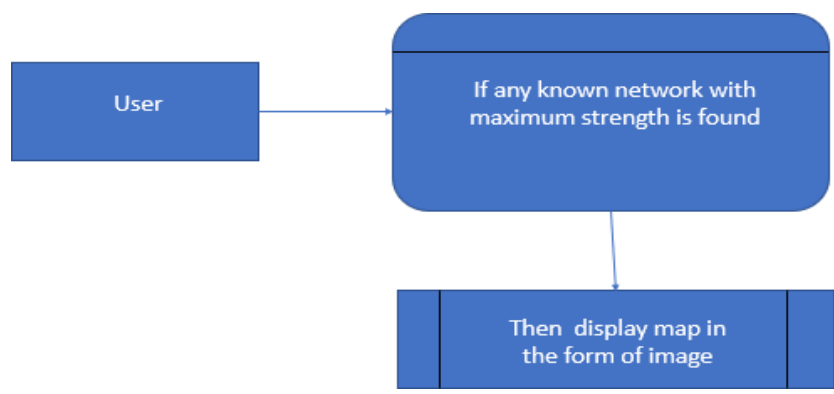

Fig. 5. DFD Level 1

7) Level 2 DFD: In level 2, the user can select a destination then the application will show the direction in the form of text.Also, the application can speak directions. 


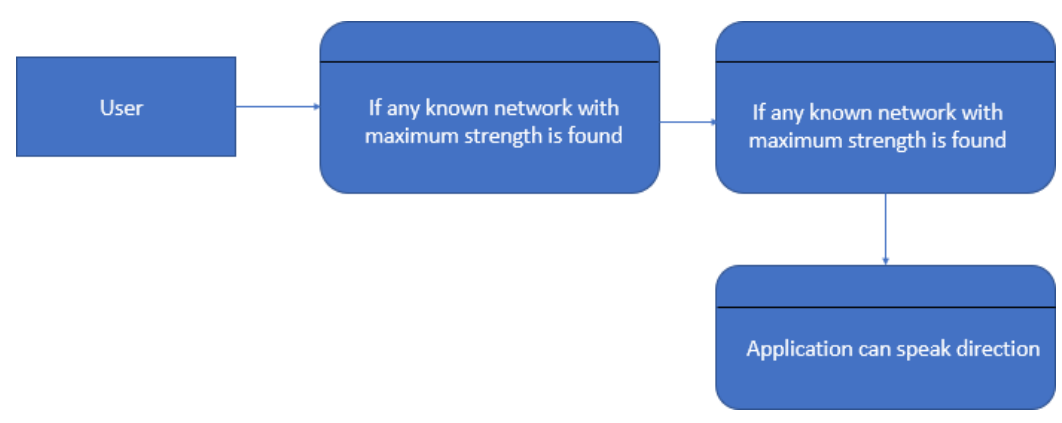

Fig. 6. DFD Level 2

8) Level 3 DFD: In level 3, if application could not identify any known then application will show default map in the formof image.

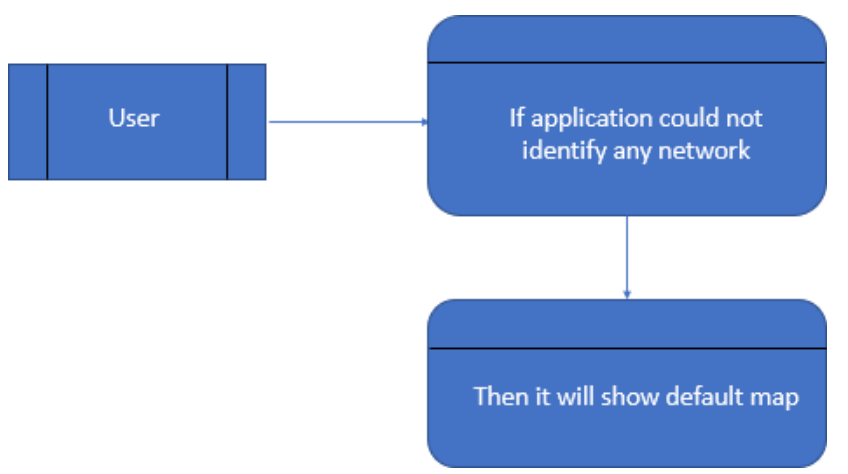

Fig. 7. DFD Level 3

\section{Expected Output}

In this project, we are expecting that the application will navigate the user the destination using WiFi signals. Followingare the 2 cases :

A. WiFi not Found:

In this case, we are expecting that the application will display the default map to the user in the form of image.

B. WiFi Found :

In this case, we are expecting that the application will display the current position of user on the map to the user in the form of image. Also, if the user selects the destination then the application should show the path to the user in the form of text and also speak the path.

\section{Actual Output}

The following figures give us a brief idea of how the systemwill work :

\section{A. Main Activity}

This is the main screen of the application. Through this screen, the user will be able to navigate to any destination. This activity contains 3 elements as follows :

- Connected WiFi : It shows the connected WiFi on the device along with its strength.

- Map : It shows the default map if there is not known WiFiavailable. If a known WiFi is available then it shows the current position of the user in the map.

- Spinner : It shows the destination options available togo from the current place.

In this activity, user can observe two cases for navigation purpose :

- WiFi not found It shows the default map in the form of an image to the user.

- WiFi found It shows the current position of the user on the map. If user selects the destination from the spinner, then the application show the direction to the destination in the form of text and speech to the user. 


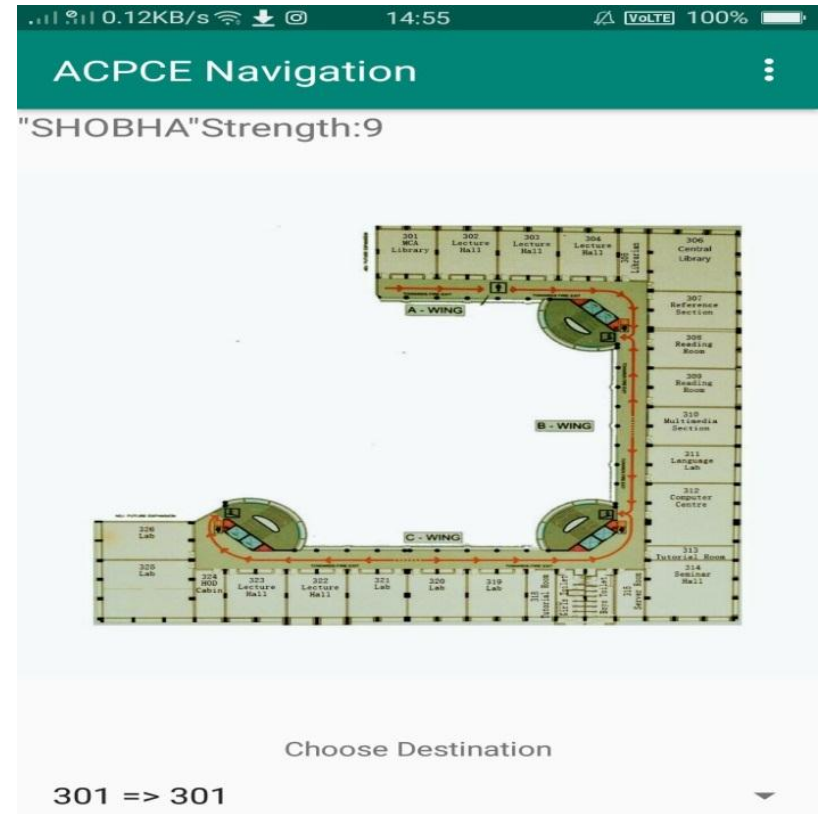

Fig. 8. Main Activity

\section{B. WiFi Strength Activity}

This activity is accessible from the main activity. When we click on pop up button on top rightmost corner on the main activity, WiFi strength activity gets started. This activity contains all the nearest available WiFi networks along with their strength. This activity is invoked from main activity afterevery 5 seconds.

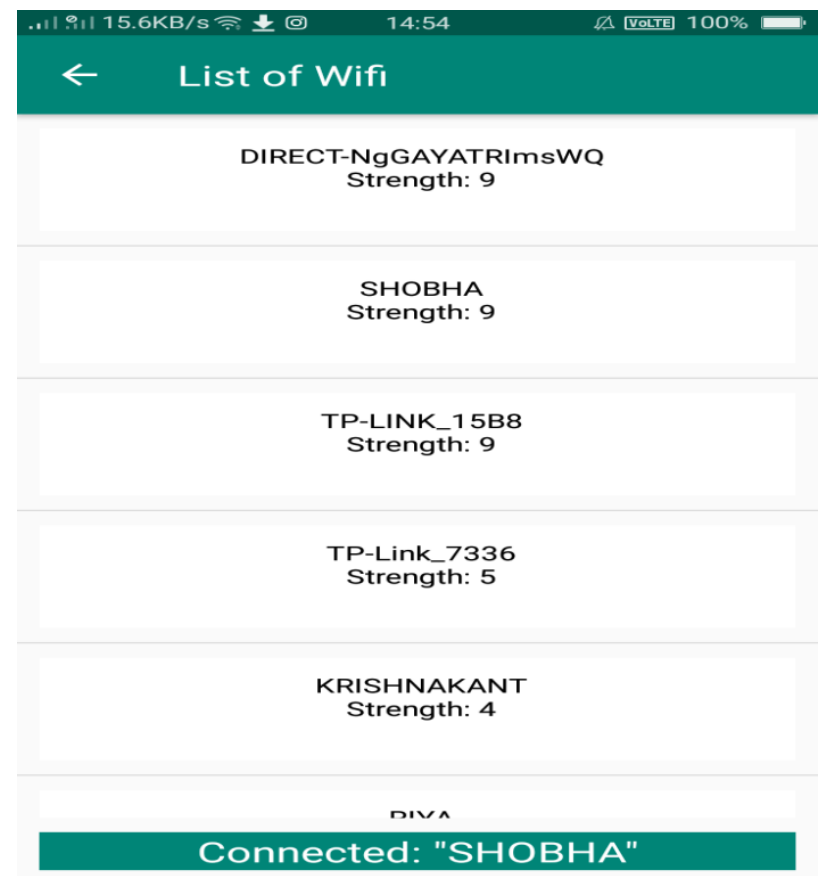

Fig. 9. WiFi Strength Activity

\section{List Adapter}

This activity is accessible from the WiFi Strength activity. When we click on pop up button on top rightmost corner on the main activity, WiFi strength activity gets started. In this, the list which appears is aligned properly with the help of List Adapter Activity. This activity takes care of displaying the WiFi network and its strength as a single element in the list. 


\section{Cases}

The following are the two cases which we will observe for navigation :

1) When no Wi-Fi network is found: In this case, the application will show the default map in the form of an image to the user.

..11 $910.30 \mathrm{~KB} / \mathrm{s}$ 드 $23: 08$
ACPCE Navigation
"SHOBHA"Strength:9

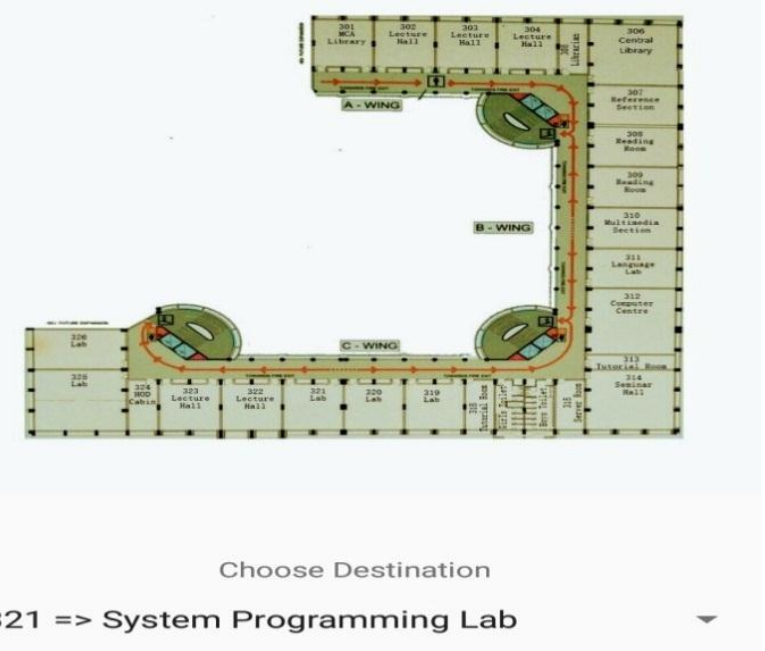

Fig. 10. Output when no Wi-Fi is found

Also, an alert will be generated saying no wifi network available as shown below :

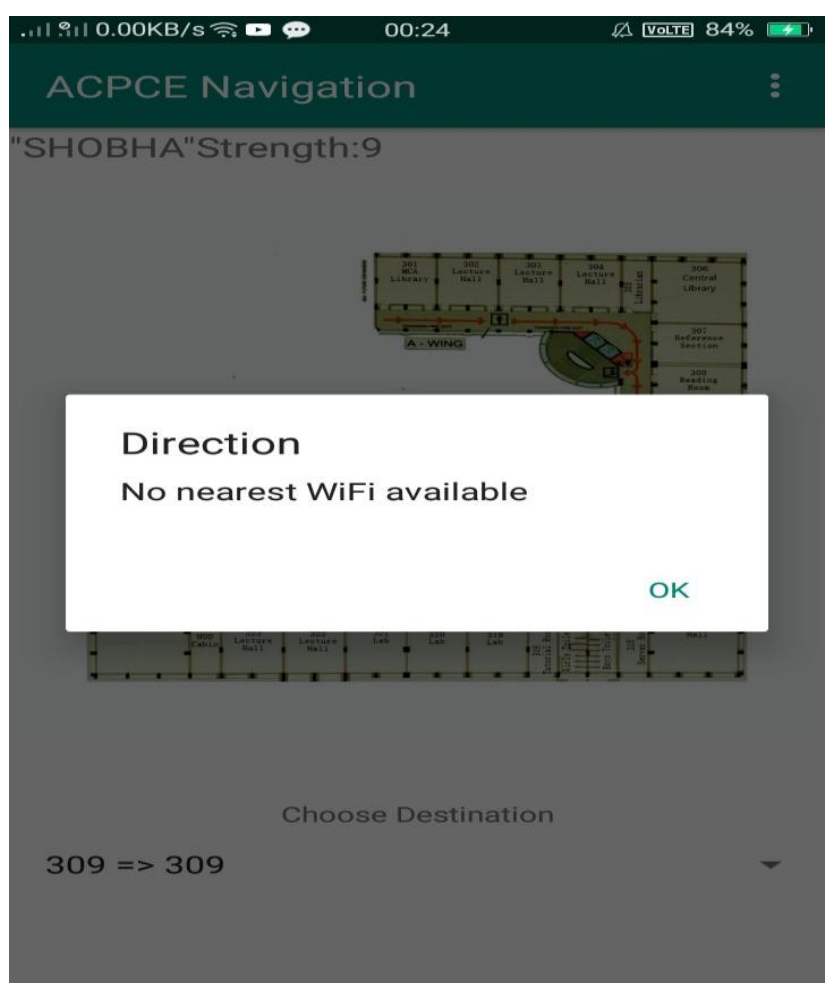


2) When Wi-Fi network is found: In this case, the appli- cation will show the current position of the user on the mapin the form of an image to the user.

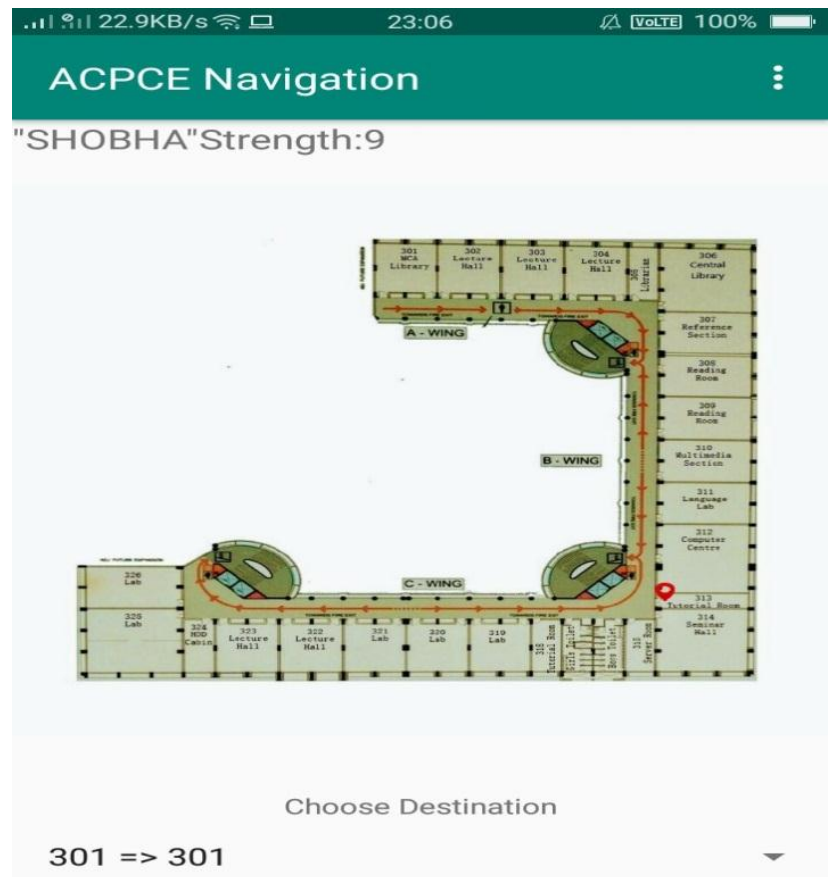

Fig. 12. Output when Wi-Fi is found

3) When the Wi-Fi network is found and the user chooses destination: In this case, the application will show the current position of the user on the map in the form of an image to the user. Also, the application will show the directions to the specific destination chosen by the user by means of text and speech.

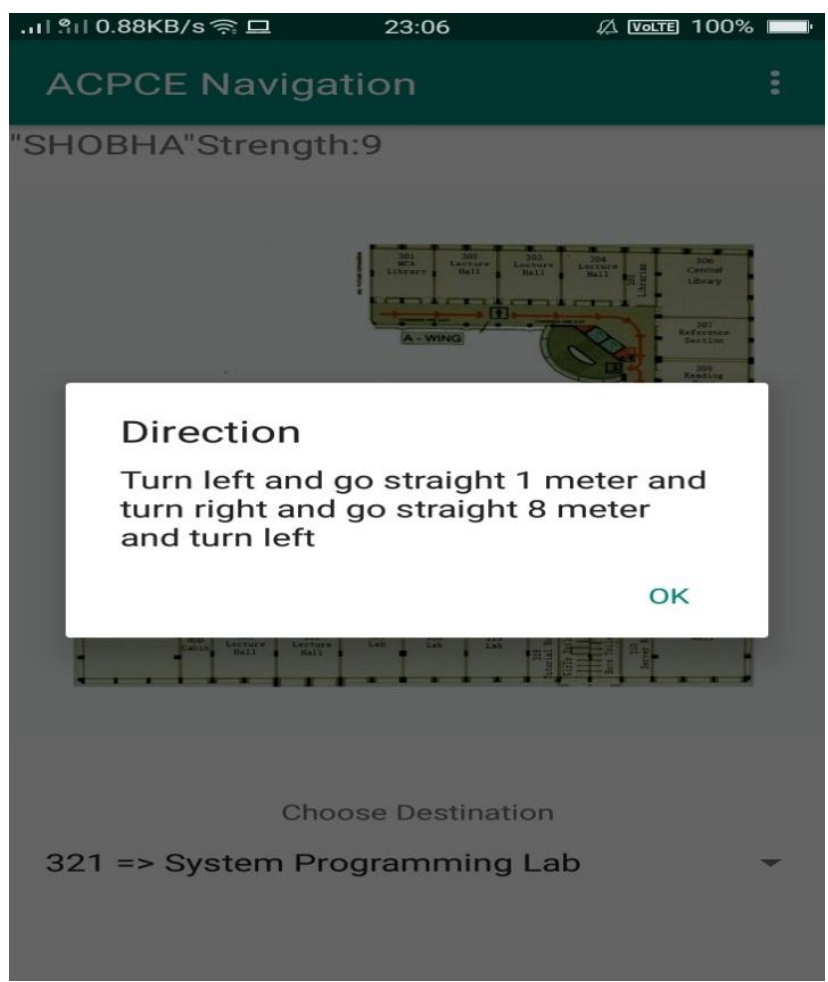

Fig. 13. Output when Wi-Fi is found and destination is chosen 


\section{Result Analysis}

The proposed model is based on Wi-Fi technology. From the experimental result, we see that for proper navigation we need to turn on GPS and Wi-fi. The analysis of the result is tabled below:

Table I. Result analysis of navigation system

\begin{tabular}{|c|c|c|c|}
\hline $\begin{array}{c}\text { Test } \\
\text { Case ID }\end{array}$ & Test Case & Input & Result \\
\hline 1 & Users need to turn on mobile Wi-Fi. & Turn on mobile $\mathrm{Wi}-\mathrm{Fi}$ & Pass \\
\hline 2. & $\begin{array}{l}\text { User can scan available Wi-Fi networks and } \\
\text { their strength }\end{array}$ & $\begin{array}{l}\text { Scan available Wi-Fi networks and their } \\
\text { strength }\end{array}$ & Pass \\
\hline 3. & $\begin{array}{l}\text { User can select the destination then } \\
\text { application will show direction in form of text }\end{array}$ & Select destination & Pass \\
\hline 4. & $\begin{array}{l}\text { If the app could not identify any known } \\
\text { network it will show the default map image. }\end{array}$ & $\begin{array}{l}\text { If the app could not identify any known } \\
\text { network it will show the default map } \\
\text { image. }\end{array}$ & Pass \\
\hline 5. & If the user did not turn on mobile Wi-Fi. & Did not turn on mobile Wi-Fi & Fail \\
\hline 6. & If the user did not scan available networks & Did not scan available networks & Fail \\
\hline
\end{tabular}

\section{Conclusion and Future Enhancement}

This project is a small attempt at delivering an efficient but affordable Indoor Navigation System with the flexibility to produce output through two means alternatively, text and image. This will contribute to finding the required destination in an unknown place and would be a small step in consideration of ease in access to modern technology for the differently- abled section in our society.

This application would certainly benefit users who are unfamiliar with a place. Tourists would have a better experience if they could navigate confidently inside a tourist attraction without any assistance. In places such as museums and art galleries, the application could be extended to plan for the most optimal or 'popular' routes. Such a system could also be integrated at airports to navigate passengers to their boarding gates. Similarly, an indoor navigation system could also benefit local users who have previously visited the location but are still unaware of the whereabouts of some of the desired items. These include supermarkets, libraries, and shopping malls.

In the future, we are expecting to show the directions on the map also which will surely increase the reliability from the user's point of view. Also, we are expecting to add one more feature that is search destination via a particular location. Also,we will make this application feasible for other platforms

\section{Acknowledgement}

I would gratefully and sincerely appreciate Prof. Rakesh Suryawanshi. Their inspiring guidance, rich experience and sustained encouragement enabled me to develop an intensive understanding of my research area. Without the generous help of my supervisor, this work would not have been possible. I thank him for his kind support and helpful suggestions during the discussions in my paper presentation.

\section{References}

[1] Roy Want, Andy Hopper. The Active Badge LocationSystem. January, 1992

[2] Farhan Manzoor, Yi Huang, Karsten Menzel. Passive RFID-based Indoor Positioning System, An Algorithmic Approach. IEEE 2010.

[3] M Paciga, Hanan Lutfiyya. Herecast : An open infrastruc- ture for location based services using WiFi. September, 2005.

[4] Yatin Chawathe, Sunny Consolvo. Place Lab: Device Positioning Using Radio Beacons in the Wild. May, 2005.

[5] C.P.Rahul Raj, SheshuBabu Tolety. QR code based navi- gation system for closed building using smart phones. IEEE 2003.

[6] Mashood Mukhtar,"GPS based Advanced Vehicle Tracking and Vehicle Control System", International Journal of Intelligent Systems and Applications(IJISA), vol.7, no.3, pp.1-12, 2015. DOI: 10.5815/ijisa.2015.03.01

[7] Fatma Boufera, Fatima Debbat, Lounis Adouane, Mohamed Faycal Khelfi,"Mobile Robot Navigation using Fuzzy Limit-Cycles in Cluttered Environment", International Journal of Intelligent Systems and Applications(IJISA), vol.6, no.7, pp.12-21, 2014. DOI: $10.5815 /$ ijisa.2014.07.02

[8] Hossam Abdel Rahman Mohamed,"A Proposed Model for Radio Frequency Systems to Tracking Trains via GPS(The Study for Egyptian National Railways)", International Journal of Intelligent Systems and Applications(IJISA), vol.6, no.4, pp.76-83, 
2014. DOI: 10.5815/ijisa.2014.04.08

[9] Ahmed k. Daraj, Alhamzah T. Mohammad, Mahmood F. Mosleh, "Indoor Localization Enhancement Based on Time of Arrival Using Sectoring Method", International Journal of Intelligent Systems and Applications(IJISA), Vol.12, No.3, pp.1-7, 2020. DOI: 10.5815/ijisa.2020.03.01

[10] Youssef N. Naggar, Ayman H. Kassem, Mohamed S. Bayoumi, " A Low Cost Indoor Positioning System Using Computer Vision", International Journal of Image, Graphics and Signal Processing(IJIGSP), Vol.11, No.4, pp. 8-25, 2019.DOI: 10.5815/ijigsp.2019.04.02

\section{Authors' Profiles}

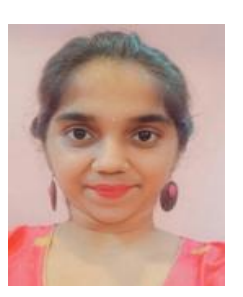

Gayatri Hushe was born in Mumbai, Maharashtra, India on October 19, 1999. She is currently pursuing her Bachelor's Degree in Computer Engineering from A. C. Patil College of Engineering from the University of Mumbai., Maharashtra, India. Through this paper, she is attempting to bring innovation to the Computer Science field.

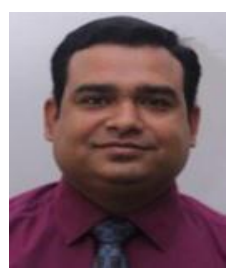

Rakesh Suryawanshi was born in Dhule, Maharashtra, India on January 11, 1980. He has been author of more than 7 journals. He received the B.E and M.E in Computer Engineering from NMU, Jalgaon and Mumbai in 2001 and 2009 respectively. He is currently HOD of Computer Department A. C. Patil College of Engineering. He has been the guide for many projects.

How to cite this paper: Gayatri Hushe, Rakesh Suryawanshi, " WiFi Based Indoor Navigation System for Closed Buildings Using Smart Phones ", International Journal of Engineering and Manufacturing (IJEM), Vol.11, No.3, pp. 35-44, 2021. DOI: 10.5815/ijem.2021.03.04 